\title{
Olhar o magistério "no próprio espelho": 0 conceito de profissionalidade e as possibilidades de se repensar o sentido da profissão docente 1
}

\author{
Ana Maria Simões Coelhoi \& Júlio Emílio Diniz-Pereiraii \\ Universidade Federal de Minas Gerais, Brasil
}

Resumo

Em seu livro Ofício de Mestre - Imagens e auto-imagens, o Professor Emérito da Universidade Federal de Minas Gerais, no Brasil, Miguel Arroyo, levanta as seguintes questões sobre o magistério: "Como a categoria pensa em si mesma? No espelho dos outros ou no próprio espelho?". Ao deixar se encantar pela "ilusão da profissionalização" - e a fortíssima influência que a vertente funcionalista exerce sobre esse conceito -, o magistério parece insistir em olhar para si mesmo "no espelho dos outros". Neste artigo, por meio da discussão dos conceitos de profissionalização, profissionalismo e profissionalidade e de uma revisão das principais vertentes da sociologia das profissões, discutimos as seguintes perguntas sobre esse tema: o que significa considerar que o magistério constitua, de fato, uma profissão? Quais as implicações de nos referirmos aos conceitos de profissionalização, profissionalismo e profissionalidade na descrição da atuação e das expectativas colocadas para o professor como profissional? Quais as possibilidades de se repensar o sentido do magistério a partir do conceito de profissionalidade? Ao final, defendemos a utilização do conceito de profissionalidade para se discutir a especificidade da profissão docente - ou seja, fazê-la olhar "no próprio espelho" - e que este abre novas possibilidades para se repensar o sentido do magistério.

Palavras-chave

Profissão docente; Profissionalidade; Sociologia das profissões; Brasil 


\section{Introdução}

Comumente pensamos nas diferentes ocupações como profissões. No Brasil, como em outros países, a palavra 'profissão' é usada para designar diferentes tipos de atividades de trabalho, desde as mais prestigiosas até as mais simples. Mas, nos meios especializados, não se utilizam os termos 'atividade', 'ocupação' e 'profissão' como sinônimos. No caso específico do magistério, há uma polêmica sobre o estatuto profissional da docência, uma vez que o sentido dado ao conceito de profissão por uma das mais tradicionais linhas de estudo das profissões - a corrente funcionalista - exclui muitas ocupações que não se enquadram nas exigências de classificação propostas, entre elas o magistério da Educação Básica. Neste artigo, perguntamos: o que significa considerar que o magistério constitua, de fato, uma profissão? Quais as implicações de nos referirmos aos conceitos de profissionalização, profissionalismo e profissionalidade na descrição da atuação e das expectativas colocadas para o professor como profissional? Quais as possibilidades de se repensar o sentido do magistério a partir do conceito de profissionalidade?

\section{Profissionalização: 0 que diz a Sociologia das Profissões}

O campo que se tornou conhecido como Sociologia das Profissões ${ }^{2}$ produziu contribuições em várias tradições epistemológicas. A vertente funcionalista desenvolveu-se a partir das ideias de Durkheim e reúne "o conjunto das teorias que vêem nas profissões formas sociais que contribuem para o funcionamento harmonioso do sistema social" (Le Bianic, 2005, p. 30; tradução livre). Um dos expoentes da vertente funcionalista da Sociologia das Profissões foi o sociólogo norte-americano Talcott Parsons que, assim como outros funcionalistas, defendeu que o principal critério que distingue uma profissão é o conhecimento especializado. Entretanto, para que os saberes possam dar origem a uma profissão eles devem "ser funcionais do ponto de vista do equilíbrio do sistema social no seu conjunto, quer dizer, dotados de um certo valor na sociedade considerada" (Le Bianic, 2005, p. 39; tradução livre). Parsons apresenta uma visão abstrata e ideal das profissões, partindo do princípio de que os grupos profissionais não são afetados pela ideologia ou pelas classes sociais. A vontade de servir a sociedade (o "ideal de serviço") e, portanto, uma atitude altruísta caracterizaria o universo profissional. 
A abordagem funcionalista tem sido criticada quanto ao que postula com respeito às relações entre os saberes e as profissões, uma vez que ela coloca ênfase nos conhecimentos teóricos como legitimadores destas, mas não define exatamente até onde eles devem ir - enfim, quanto é preciso saber de quê, quando se trata de situações concretas. Chapoulie (1973) critica o fato de que as análises funcionalistas separam "o saber profissional de suas condições de produção, de difusão e de utilização, quer dizer, das instituições e dos grupos que se atribuem o papel de o conservar, desenvolver e de ser, junto aos leigos, as testemunhas de sua existência" (p. 96).

No caso da profissão docente, a definição dos saberes profissionais é um tema que está longe de ser consensual, não apenas tendo em vista os diferentes níveis de ensino e as respectivas exigências, mas também o fato de que, tradicionalmente, no Brasil e em outros países, a formação dos professores das etapas mais adiantadas da Educação Básica tem como referência o campo do saber que irão lecionar e não os conhecimentos do campo da Pedagogia que, em geral, são secundarizados nos currículos dos cursos de formação docente.

Se os funcionalistas têm uma visão estática e monolítica dos saberes como esteio das profissões, os quais seriam assimilados durante a formação universitária, a perspectiva interacionista introduz a visão de que os saberes são constantemente construídos e negociados pelos profissionais ao longo de sua vida e carreira, nos contatos com seus clientes e com aqueles com quem trabalham, em um processo de socialização em que os aprendizes, aos poucos, assumem a perspectiva dos profissionais, sua maneira de ver 0 mundo, e se distanciam dos não iniciados. Isto significa que esses saberes não têm que ser exclusivamente acadêmicos ou científicos, de modo que qualquer tipo de conhecimento pode dar origem a uma profissão (Le Bianic, 2005).

Um dos autores mais destacados da vertente interacionista foi o sociólogo norte-americano Everett Hughes. Para ele, cada profissão integra um sistema de trabalho que inclui funções mais respeitáveis e outras subalternas, em uma distribuição de tarefas hierarquizada. Ele dá o exemplo da profissão médica, em que muitas funções vão sendo delegadas a enfermeiras, as quais, na medida em que atingem um melhor status profissional, transferem atividades 'inferiores' a cuidadoras, e estas repassam 
outras ao pessoal que faz a limpeza, etc. O sistema interacional, no caso da profissão de professor, inclui não apenas o professor e o aluno, mas também os pais, a direção da escola, os funcionários de diferentes níveis, enfim, todos aqueles que, de algum modo, 'interferem' no trabalho do professor (Hughes, 1964).

Hughes (1964) também introduz a ideia de que as profissões significam uma "licença para realizar certas atividades que outros não podem, e fazê-lo em troca de dinheiro, bens ou serviços", e ainda "um mandato para definir o que é conduta adequada de outros no que concerne ao seu trabalho" (p. 78; tradução livre). Nas palavras de Dubar (1997), a licença "é a autorização legal para exercer algumas atividades que outros não podem exercer" e o "mandato é a obrigação legal de assegurar uma função específica" (p. 133). A licença e o mandato constituem "a manifestação primordial da divisão moral do trabalho", que Hughes (1964) define como "os processos pelos quais diferentes funções morais são distribuídas entre os membros da sociedade, tanto como indivíduos como tipos ou categorias de indivíduos" (p. 80; tradução livre). Os profissionais possuidores de licença e mandato têm, muitas vezes, que entrar em contato e guardar segredo sobre uma espécie de "conhecimento culpado", embaraçoso, que não seria tolerado em outra circunstância que não o exercício de sua profissão (Hughes, 1964).

Para Hughes (1964), o magistério da Educação Básica, como profissão intelectual, encontrava-se, na verdade, na sociedade americana, em posição subordinada, e não apenas aos poderes públicos, de maneira que 0 exercício profissional podia ser considerado, no mínimo, ambíguo, senão francamente inútil e frustrante! Pesquisas mais recentes sobre a situação atual dos professores norte-americanos indicam que as condições de exercício do magistério naquele país não melhoraram muito (Larson, 2014; Popkewitz, 1997; Zeichner, 2008).

A abordagem interacionista-simbólica ampliou o conceito de "profissão" e abriu espaço para que o poder profissional e o monopólio que ele cria sobre as atividades próprias da profissão fosse criticado, na medida em que apontou a distância existente entre "os saberes oficiais da profissão" e as tarefas que os profissionais realmente fazem na prática (Le Bianic, 2005). Evidenciou-se a inadequação do modelo funcionalista para a compreensão do exercício profissional concreto, tendo em vista as diferenças entre eles. Os 
grupos profissionais deixaram de ser estudados como objetos teóricos e passaram a ser abordados como objetos da prática cotidiana (Chapoulie, 1973). As análises interacionistas revelaram que, contrariamente aos atributos positivos enfatizados pela abordagem funcionalista, na verdade, as profissões "se caracterizam antes pelo seu egoísmo ou uma busca de poder e do monopólio econômico", de modo que "sua posição privilegiada deve ser denunciada" (Le Bianic, 2005, p. 46; tradução livre). Entretanto, se as pesquisas empíricas realizadas a partir da visão fenomenológica interacionista permitiram questionar a aplicabilidade do modelo parsoniano, colocando em evidência o papel dos atores sociais nas suas práticas cotidianas, um dos limites desse enfoque é que ele se restringiu aos aspectos microssociológicos sem antes "estruturar o campo de ação" dos agentes sociais (Barbosa, 1993, p. 7). Além disso, a proposta de estudo formulada por Hughes e outros pesquisadores dessa linha para o estudo das profissões e semiprofissões é também de difícil aplicação a outras ocupações, principalmente os "assalariados menos qualificados das grandes empresas" (Dubar, 1997, p. 140)

A teoria funcionalista e a abordagem interacionista das profissões foram criticadas por autores da tradição crítica da Sociologia das Profissões, que produziram trabalhos nas linhas neo-weberiana e marxista. Entre esses destacaram-se o inglês Terence Johnson, que produziu trabalhos na linha marxista, e a norte-americana Magali Larson, que incluiu em seus estudos referências neo-weberianas e marxistas. Enquanto a contribuição do interacionismo se deu na dimensão microssociológica, "a partir das tarefas efetivamente realizadas pelas profissões nos seus contextos de trabalho" (Le Bianic, 2005, p. 47; tradução livre), os estudos desses autores ampliaram o foco de modo a analisar as profissões dentro da estrutura social como um todo. Além disso, de acordo com Le Bianic (2005), eles têm em comum o fato de rejeitarem a visão otimista dos funcionalistas, para quem "as profissões são um saber positivo, suscetível de melhorar o sistema social" (p. 47; tradução livre). Os trabalhos da vertente neo-weberiana procuram aplicar a teoria da monopolização de Weber às estratégias de grupos profissionais para reservarem domínios exclusivos de atuação em relação a certos campos do saber. Os estudos da vertente marxista enfatizam "a posição das profissões na estrutura de classes e os mecanismos de dominação e de repartição do poder no seio da sociedade" (Le Bianic, 2005, p. 47; tradução livre). 
Johnson (cit. em Bonelli, 1993) critica particularmente a crença das análises estrutural-funcionalistas em uma pretensa neutralidade dos grupos ocupacionais em relação às classes sociais. Para o autor, ao contrário, as profissões constituem uma forma de controle e poder. Desse modo, elas não se organizam para atender a necessidades sociais, mas, inversamente, tratase de "uma imposição dessas necessidades e do formato dos serviços prestados" (Johnson, cit. em Bonelli, 1993, p. 32). De acordo com Johnson (cit. em Le Bianic, 2005), o "profissionalismo só pode aparecer onde os processos ideológicos e políticos que sustentam [essa ideologia] coincidem com as necessidades do capital" (p. 50; tradução livre).

Em seu livro The rise of professionalism: A sociological analysis, publicado em 1977, Larson faz, inicialmente, uma reconstrução histórica das origens e fortalecimento das profissões a partir do final do século XVIII nos Estados Unidos e na Inglaterra. A autora mostra, em seguida, que a constituição de um mercado no sentido moderno exige a produção de uma mercadoria e, como o trabalho profissional produz bens intangíveis que estão "intimamente associados à pessoa e à personalidade do produtor", segue-se que "os próprios produtores têm que ser produzidos", isto é, "os profissionais têm que ser adequadamente treinados e socializados de modo a prover serviços reconhecidamente distintos para troca no mercado profissional" (Larson, 1977, p. 14; tradução livre) A organização do mercado profissional, por sua vez, exige que a educação dos novos profissionais seja padronizada, sendo o conteúdo cognitivo da formação de cada profissão exclusivo. Larson (1977) assinala que "numa situação de mercado a garantia contra eventuais riscos tende a tomar a forma de monopólio ou, pelo menos, de proteção especial pelas autoridades públicas" (p. 15; tradução livre). No caso das profissões, o Estado sanciona e legitima a demanda por um sistema de educação monopolístico com base na alegada superioridade do produto oferecido pelos profissionais. A autora revela também a importância, para a manutenção do monopólio obtido, da profissão controlar sua base cognitiva, isto é, a produção do conhecimento que a fundamenta, que possibilitará a apropriação e domínio de novos saberes, e, ao mesmo tempo, a formação dos profissionais.

Larson (1977) considera as profissões como um projeto coletivo que visa obter o controle do mercado, sendo que o cerne desse projeto de 
profissionalização é a produção dos próprios profissionais, que são aqueles que realizam os serviços. Para o sucesso de tal projeto, a autora destaca como fundamental que as profissões se aliem à universidade, onde o conhecimento pertinente às mesmas é produzido. Quanto mais a base cognitiva é padronizada e científica e a preparação de novos profissionais institucionalizada e controlada pela profissão, mais favorável é a situação para a profissão, que pode, até, caso considere necessário, regular a entrada no mercado de novos profissionais.

A referida autora (Larson, 1977) aborda também questões relativas ao desenvolvimento do modelo burocrático de organização da estrutura ocupacional. O magistério da Educação Básica é considerado como uma dessas profissões organizacionais, pois funciona dentro do sistema escolar, no qual, frequentemente, o professor ocupa um lugar subalterno na hierarquia. As profissões organizacionais não são independentes no sentido de atuarem livremente no mercado profissional. Larson (1977) relata de que maneira, nas primeiras décadas do século $X X$, o desenvolvimento do ensino médio nos Estados Unidos impulsionou a docência no sentido de se afirmar como profissão. Entretanto, os professores, ocupando posições subordinadas na burocracia do sistema escolar, não tiveram, naquele momento, solidariedade e coesão suficientes para assumir o caminho da profissionalização por meio da capacitação em conhecimentos especializados e aquisição de competência com base em uma "ainda incerta ciência da pedagogia" (Larson, 1977, p. 184). A autora assinala que, devido a essa circunstância, os avanços conseguidos pelos professores, muito mais do que no caso de outras semiprofissões, foram devidos à atuação dos sindicatos. Ela explica também de que maneira, em algumas profissões organizacionais - por exemplo, no caso dos professores da Educação Básica -, o projeto de profissionalização é mediado pela organização e passa primeiro por ela, uma vez que o monopólio sobre a área funcional relativa à educação formal das crianças, em que atuam, é assumido pela própria organização, e não pelo grupo profissional.

Embora o termo profissionalização possa ser usado, como o emprega o sociólogo francês Jean Michel Chapoulie (1973), seguindo a tradição sociológica francesa, para designar "o processo segundo o qual um grupo profissional tende a organizar-se segundo o modelo das profissões 
estabelecidas" (p. 89), é importante destacar que tanto Johnson quanto Larson consideram a profissionalização como um processo historicamente localizado e específico de certas ocupações. Interessado em desvendar as relações das profissões com o poder, Johnson (cit. em Costa, 1995) entende que a profissionalização é "uma forma de controle político do trabalho, conquistado por um grupo social, em determinado momento histórico" (p. 89). Johnson (cit. em Costa, 1995) refere-se ainda à profissão como "um meio de controlar uma ocupação" (p. 89), enquanto para Larson (2014) a profissão é "uma forma historicamente específica de organizar o trabalho." (p. 8).

Em comentário recente sobre sua obra, Larson (2014) reflete também sobre a situação da profissão docente, particularmente no Ensino Fundamental nos Estados Unidos, em que os professores são "a maior categoria de 'profissões organizacionais' que servem o público" (p. 8). A autora considera que "os professores estão sob grande estresse hoje e mesmo sob ataque direto em muitas partes do país" (Larson, 2014, p. 8). Esclarece que os professores exercem sua profissão no interior de grandes e heterônomas organizações, os "distritos escolares", que podem ser comparados, aqui, aos sistemas municipais de ensino. Desse modo, mesmo atuando em escolas pequenas, os professores "ainda são os implementadores subordinados de políticas decididas alhures" (Larson, 2014, p. 12). E diante da "tempestade que ameaça os professores", a autora volta à pergunta que pairava sobre os professores universitários grevistas de San Francisco em 1968: "É 'profissional' sindicalizar-se"? 3 (Larson, 2014, p. 12). A autora registra que "os sindicatos têm estado sob ataque em todos os setores de trabalho desde meados dos anos 1970, mas, no ensino de 4 a 12 anos, eles são frequentemente apresentados como o oposto de profissionalismo" (Larson, 2014, p. 12). Para explicar a questão, Larson retoma um episódio da história da sindicalização dos professores, nos Estados Unidos, quando Margaret Haley, em 1904, se tornou a primeira mulher a discursar para a assembleia da Associação Nacional de Educação daquele país. Além de se referir aos salários inadequados, denunciou também as inseguranças no emprego e na aposentadoria, as salas de aula lotadas e o trabalho exaustivo:

a falta de reconhecimento do professor como um educador no sistema escolar, devido à tendência para "industrializar a educação" [factoryizing education], fazendo do professor um autômato, uma mera ferramenta de fábrica, cujo trabalho seria colocar em prática mecanicamente e sem questionamento as 
ideias e ordens daqueles investidos com a autoridade da posição, e que podem ou não saber as necessidades das crianças ou como provê-las. (Haley, cit. em Larson, 2014, p. 12; ênfase de Larson, tradução livre)

Acrescentou que "os sindicatos seriam a única maneira de alcançar o 'ideal educacional' pela aplicação 'da mais avançada teoria da educação'" (Haley, cit. em Larson, 2014, p. 12). Larson (2014) destaca que Haley "fundiu o profissionalismo dos professores com suas condições de trabalho e exigiu o compartilhamento do poder" (p. 12). Mas, então, como agora o poder continua sendo negado aos professores e aos seus sindicatos? Nos Estados Unidos, ele teria sido, outrora, trocado por autonomia na sala de aula e, para alguns poucos, egressos de certos programas de formação, por um lugar na administração. Hoje os professores continuam enfrentando o "poder administrativo centralizado, a liderança tecnocrática feita por pessoas de fora, e um modelo empresarial pelo qual os princípios de mercado penetram no Estado disfarçados de reforma" (Larson, 2014, p. 12).

A polêmica em torno da questão da profissionalização da profissão docente tem em Mariano Fernandez Enguita (1991) um de seus autores mais conhecidos. Enguita desenvolveu o argumento de que a profissão docente é uma semi-profissão, por reconhecer nela características que a colocam a meio caminho entre a situação dos profissionais que exercem profissões tidas como clássicas e a situação dos trabalhadores assalariados. Pela relevância que assume neste texto, trataremos desse tema em um item em separado, a seguir.

\section{O magistério como uma semiprofissão}

O modelo clássico geralmente tomado como referência para o entendimento do que seja uma profissão é o das profissões de advogado, engenheiro e médico. Assim, Enguita (1991) identifica cinco características principais para a definição de uma ocupação como profissão, no sentido clássico ${ }^{4}$. Em relação a essas características que constituem o estatuto profissional das profissões clássicas, o que se observa no caso dos docentes é que nunca ocorre uma identificação completa em relação a cada uma, pois, quando as comparamos com a situação que caracteriza o docente como profissional, sempre fica faltando algo. Por outro lado, a situação dos professores também não é a mesma daqueles que ocupam o outro extremo do arco ocupacional, que seriam os operários da indústria. 
Para compreender melhor a situação dos professores, é importante destacar o que ocorre em relação a algumas dessas características. Quanto à licença, por exemplo, Enguita (1991) chama a atenção para o fato de que a legislação não outorga a capacidade de ensinar exclusivamente aos professores, havendo "plena liberdade para o ensino informal", enquanto "ao contrário, não poderíamos encontrar, por mais que buscássemos, uma medicina ou uma advocacia não regulamentadas" (p. 45). Também no que se refere à competência, a situação dos docentes é complicada, uma vez que a educação é um tema sobre o qual, como assinala o autor, "qualquer pessoa se considera com capacidade para opinar", de modo que o trabalho do professor "pode ser julgado e o é por pessoas alheias ao grupo profissional" (Enguita, 1991, p. 45). A questão da independência também é apresentada como problemática pelo autor, pois os professores não são completamente autônomos em relação ao seu público, uma vez que os pais e alunos têm direito a participar na gestão das escolas, ainda que os docentes tenham maioria. Quanto a este último ponto, importa fazer uma distinção entre autonomia em relação à própria atuação profissional e o que poderia ser uma completa independência quanto a possíveis interferências por parte do público afetado por essa atuação. Levando em conta o sentido e o contexto do trabalho do professor de maneira mais global, cabe refletir se uma total independência seria desejável. Talvez seja mais importante estabelecer os critérios e âmbitos de atuação dos participantes no processo.

Ironicamente, a profissão docente parece se aproximar mais dos quesitos distintivos das profissões liberais no que se refere ao fato de se acreditar que ela deva ser exercida em virtude de uma "vocação", o que significaria exercê-la "pelo desejo de servir a seus semelhantes", com a consequência - distorcida, no caso dos professores - de que "seu trabalho não pode ser pago, porque não tem preço, seu exercício é 'liberal' e sua retribuição toma a forma de "honorários"' (Enguita, 1991, p. 44). No caso dos professores, o que se verifica, na prática, é o aviltamento dos salários pagos, isto é, a fixação de um preço irrisório pelo trabalho prestado, mesmo que ele seja considerado - pelo menos no discurso - um dos mais importantes pela sociedade, e não a retribuição sob a forma de uma remuneração digna.

Se o trabalho docente não pode ser caracterizado exatamente como uma profissão no sentido clássico, ele também não pode ser completamente 
identificado ao de proletários como os operários da indústria. Ao discorrer sobre as características que aproximam o professor de um trabalhador proletarizado, Enguita (1991) esclarece, antes de mais nada, que "um proletário é uma pessoa que se vê obrigada a vender sua força de trabalho" (p. 46), e acrescenta que, hoje em dia, a grande maioria dos docentes é assalariada. O autor aborda, em seguida, outras características, como a produção de mais-valia pelo professor, que ocorre tanto em relação aos do setor público quanto do setor privado, e a maneira como a perda de controle sobre o processo de trabalho dos docentes se reflete na desqualificação do posto de trabalho, em consequência da limitação da possibilidade de tomar decisões, da divisão do trabalho docente, e mesmo da maneira como o livro didático define o conteúdo que o professor deverá trabalhar.

Frente às constatações que faz, Enguita (1991) chega à conclusão de que a categoria dos docentes se encontra em uma posição ambivalente, uma vez que seu exercício profissional apresenta tanto características do que ocorre com os profissionais liberais quanto da situação dos operários. Nesse sentido, identifica a existência de tendência, não apenas para a proletarização - cujos sinais se tornam de conhecimento público por ocasião das greves do professorado, pela reiterada divulgação da pauta de reivindicações dos sindicatos -, mas também para a profissionalização, já que elementos considerados pelo autor como parte da natureza específica do trabalho docente tornam mais difícil submetê-lo a situações que levariam a uma aproximação maior da situação de proletarização. Do mesmo modo, conclui que mudanças em um sentido ou no outro não parecem prováveis e o que poderá ocorrer, segundo ele, são apenas flutuações que ora podem favorecer a profissionalização, ora o processo de proletarização. Para Enguita (1991), a situação profissional dos docentes talvez possa melhorar caso se consiga garantir "certa capacidade de controle da sociedade sobre a profissão docente e certo campo de auto regulação desta" (p. 60). Isto significa que uma certa ambiguidade quanto ao estatuto profissional do trabalho docente talvez faça parte de sua natureza e não deva ser considerada como negativa.

\section{A profissão docente e o debate profissionalização versus proletarização}

Marta Jiménez Jaén (1991), por sua vez, traz vários e importantes elementos no sentido de detalhar e esclarecer até que ponto se pode, 
realmente, falar de um processo de proletarização, no caso dos professores da Educação Básica, considerando o que afirma a sociologia marxista. A autora começa por esclarecer a visão de proletarização dos autores que escrevem a respeito fundamentados nas ideias de Harry Braverman ${ }^{5}$. Este autor se debruça sobre a questão da desqualificação do trabalho dos operários, que ele vincula ao controle exercido sobre eles a partir da fragmentação das tarefas realizadas e da separação entre o trabalho intelectual e o trabalho manual. Jaén (1991) se detém também sobre a crítica feita a essa análise por Charles Derber, que examina as especificidades do processo em relação a outros trabalhadores que não os da indústria e introduz o conceito de "proletarização ideológica" para descrever o que ocorre, por exemplo, com professores e outros tipos de funcionários. Jaén (1991) chama a atenção para o fato de que a análise sociológica feita pelos "teóricos da proletarização", quanto à categoria dos docentes, centra "a atenção em suas condições de trabalho e em suas ações enquanto trabalhadores", podendo-se resumir seus argumentos em quatro "idéias nucleares" (p. 75$)^{6}$.

Em seguida, a autora destaca a diferenciação feita por Derber, ao analisar a "proletarização" dos profissionais, entre "proletarização técnica", que "define-se em relação ao controle dos modos de execução do trabalho", e "proletarização ideológica", que "vincula-se ao controle sobre os fins do trabalho" (Jaén, 1991, p. 77). A categoria docente estaria submetida, como os profissionais, principalmente à proletarização ideológica, à qual eles reagem com estratégias de "acomodação", visando "proteger seus interesses" (Derber, cit. em Jaén, 1991, p. 78). Dentre estas, Derber (cit. em Jaén, 1991) destaca a "desensibilização ideológica", que consiste em negar que o que se perdeu seja uma parte importante do trabalho. Ela se traduz pelo abandono dos fins sociais do trabalho, que passa a ser realizado apenas de acordo com critérios científicos e técnicos. Uma segunda reação é a "cooptação ideológica", que leva a um esforço de "identificação do 'caráter ideológico e moral do trabalho' com o que é redefinido por outros" (Jaén, 1991, p. 79). Isto significa, segundo Derber (cit. em Jaén, 1991), que a "proletarização" teve efeitos bastante diferentes em relação aos profissionais, uma vez que a perda do controle sobre o trabalho no caso dos educadores, por exemplo, incide sobre os aspectos técnicos, mas é contornada, até certo ponto, pela maneira como eles reagem à proletarização ideológica. Como se pode ver, trata-se de uma questão complexa, uma vez que, embora a proletarização técnica possa 
ser, talvez, mais facilmente constatada e sentida no dia a dia, a proletarização ideológica pode ter efeitos mais deletérios sobre o profissional, tanto mais quanto esta última é supostamente 'contornada' por ele, que, devido a tal acomodação, pode ficar com a impressão de que ela não esteja ocorrendo.

Todavia, Blas Cabrera e Marta Jaén (1991) insistem na importância de não perder de vista as diferenças entre o professorado e a classe trabalhadora, devido à localização específica dos docentes na estrutura social. Para os autores, além de compreender "que a consolidação e a expansão dos sistemas educacionais têm alterado a situação tradicional e as funções do professorado", é preciso levar em conta que "em outros momentos sua posição tem sido mais independente, e superiores suas possibilidades de tomar decisões e controlar seu trabalho", de modo que mesmo que os professores estejam enfrentando "a tendência à burocratização dos sistemas educacionais e à desqualificação e separação entre concepção/execução" não é possível falar em sua "homogeneização com o trabalho manual" (Cabrera \& Jaén, 1991, p. 199). Assinalam, ademais, que os professores, como funcionários do Estado, não podem ser incorporados no "âmbito do 'trabalho produtivo'", uma vez que seu trabalho não gera mais-valia e, "justamente por sua condição de 'improdutivos'... vivem de forma específica situações como uma crise econômica" (Cabrera \& Jaén, 1991, p. 199). Por outro lado, se os professores se encontram "em uma posição de domínio em relação ao trabalho manual", isto não chega a impedir que "a própria categoria docente possa ver-se excluída de funções conceituais em seu trabalho", "já que a divisão social do trabalho tende a reproduzir-se ... tanto no interior do trabalho manual como no do trabalho intelectual" (Cabrera \& Jaén, 1991, p. 200).

Cabrera e Jaén (1991) relativizam também o alcance das alterações havidas nas condições de trabalho dos professores, pois, para eles, "o processo não tem sido tão devastador do controle e das qualificações do professorado como o tem sido no âmbito do trabalho diretamente produtivo" (p. 201). Os professores não se vêm impedidos de realizar as tarefas para as quais também estão disponíveis especialistas, sendo, em alguns casos, requalificados para tanto. E também há um limite para a perda de autonomia, pois o trabalho do professor, por sua natureza, requer uma certa liberdade para fazer adaptações tendo em vista que "se realiza com seres humanos" e, 
além disso, acontece "concretamente em salas de aula separadas onde o docente trabalha sozinho, e onde sua autoridade se apoia em critérios de legitimidade relativos à sua suposta 'superioridade intelectual' com relação ao alunado" (Cabrera \& Jaén, 1991, p. 201). Os autores advertem, entretanto, para o fato de que, como no caso do professorado, as medidas racionalizadoras são propostas e adotadas não pelo capital mas pelos administradores do Estado, cujo objetivo é "manter-se à frente dos aparelhos de Estado", e, sendo assim, o processo é "muito mais vulnerável", pois os "'administradores do Estado' têm de aparentar ... que atuam com 'neutralidade', que se trata de medidas que favorecem a sociedade em seu conjunto" (Cabrera \& Jaén, 1991, p. 202).

Tais considerações, algumas das quais feitas há mais de duas décadas, continuam atuais, pois ajudam a compreender os motivos pelos quais temos notado, na prática, uma diminuição já preocupante no número daqueles que escolhem a profissão de professor da Educação Básica pública brasileira. Em outras palavras, elas fazem sentido no contexto das reflexões que é necessário empreender sobre a realidade do trabalho docente hoje. De fato, se as particularidades dessas análises não chegam aos licenciandos, eles têm conhecimento da situação concreta dos professores. Assim, há uma percepção positiva quanto aos processos que permitem considerar o docente como um "profissional", pois estes resultam, na prática, em maior valorização do exercício do magistério e, potencialmente, em melhoria nos salários. Inversamente, os processos de proletarização são percebidos pelos jovens como negativos, talvez não tanto pelo que significam em termos das perdas relacionadas ao próprio processo de trabalho, mas por se traduzirem em desvalorização da profissão e, consequentemente, piora ou estagnação do poder aquisitivo. No contexto da sociedade em que vivemos, capitalista e consumista, os jovens buscam profissões que, talvez mais do que a satisfação e realização pessoal, possam garantir-lhes não apenas o sustento, mas um certo nível de consumo.

Em relação a esse debate sobre a questão da profissionalização versus proletarização do trabalho docente, Maurice Tardif e Claude Lessard (2007) consideram tratar-se de uma colocação do problema "binária demais", pois "as coisas são bem mais complexas" do que transparece na polarização entre "os partidários da profissionalização do ensino" e "os defensores da tese 
de sua proletarização" (p. 27). Segundo os autores, "a temática da profissionalização do ensino não pode estar dissociada da problemática do trabalho escolar e docente, e dos modelos que regem a organização" (Tardif \& Lessard, 2007, p. 28).

Tardif e Lessard (2007) não são os únicos a criticar esse binarismo em que a questão da profissionalização versus proletarização do trabalho docente é geralmente tratada na literatura da área. Vários outros autores, antes mesmos dos colegas canadenses, questionaram o chamado "discurso do profissionalismo" (Arroyo, 2000, p. 29) ou a "retórica da profissionalização" (Contreras, 2002, p. 74) - ou o que poderíamos denominar aqui de ilusão de profissionalização - e alertaram sobre "as armadilhas" (Contreras, 2002, p. 68), "os perigos e problemas associados à própria ideia de profissional" (Contreras, 2002, p. 71).

Para Arroyo (2000), por exemplo, "[0] discurso do profissionalismo é um sonho ambíguo" (p. 29). Explica porquê:

Do lado da categoria pode significar o reconhecimento e a valorização. Do lado social, pode significar a justificativa para adiar esse reconhecimento. Por falta de competência e de domínio de saberes, o reconhecimento e a valorização são sempre adiados. Quando os níveis de titulação aumentarem serás reconhecido e valorizado. Novos planos de valorização do magistério num futuro sempre adiado. O discurso da incompetência-competência não tem servido de justificativa, mais aparente do que real, para adiar esse reconhecimento? Não penso que os profissionais da Educação Básica sejam menos competentes do que outros profissionais de áreas próximas. A qualificação aumentou consideravelmente nas últimas décadas, não obstante o estatuto profissional da categoria continua indefinido, ainda imerso em uma imagem social difusa, sem contornos. (Arroyo, 2000, p. 29)

Ao tecerem tais críticas, alguns desses autores - assim como o que propomos neste texto - utilizam o conceito de profissionalidade não apenas para deixar claro os seus questionamentos, mas também para avançar no debate e apresentar novas possibilidades de se repensar o sentido do magistério.

\section{O conceito de profissionalidade, a ressignificação da ideia de vocação e as possibilidades de se repensar o sentido do magistério}

Gimeno Sacristán (1995) define o termo profissionalidade como aquilo "que é específico na ação docente, isto é, o conjunto de comportamentos, 
conhecimentos, destrezas, atitudes e valores que constituem a especificidade de ser professor" (p. 64)

Ao partir das definições de Eric Hoyle e também de Gimeno Sacristán sobre profissionalidade, José Contreras (2002) afirma que esse termo "referese às qualidades da prática profissional dos professores em função do que requer o trabalho educativo. ... não só descrever o desempenho do trabalho de ensinar, mas também expressar valores e pretensões que se deseja alcançar e desenvolver nesta profissão" (p. 74; grifos do autor). Para Contreras (2002), são três as dimensões da profissionalidade: "a) a obrigação moral; b) o compromisso com a comunidade; e c) a competência profissional" (p. 76). Mais adiante, discutiremos essas três dimensões da profissionalidade, não apenas com as posições desse autor espanhol, mas também com as ideias de outros autores sobre o tema. Antes disso, aprofundaremos um pouco mais sobre esta ideia da especificidade da ação docente - núcleo do conceito de profissionalidade.

Miguel Arroyo, a fim de compreender e esclarecer o que caracteriza e distingue o trabalho do professor, explica em seu livro, Ofício de Mestre Imagens e auto-imagens (2000), que escolheu o termo ofício porque ele remete tanto à longa memória que esse saber-fazer carrega, quanto ao fato de se tratar do que ele reconhece como um fazer de artífice, qualificado, profissional, algo de que se tem orgulho, "a defesa de uma identidade individual e coletiva" (p. 18). Para ele, a "perícia dos mestres"'" diz respeito às "artes de ensinar e educar", ao "conviver de gerações", ao "saber acompanhar e conduzir a infância em seus processos de socialização, formação e aprendizagem", e continua viva, presente e necessária (Arroyo, 2000, p. 18) Trata-se, portanto, de algo cujo conteúdo não pode, em seu entender, ser facilmente substituído por qualquer pessoa de boa vontade ou pelo que uma certa modernização tem trazido para o campo da educação. Para Arroyo (2000),

A educação que acontece nas escolas tem, ainda, muito de artesanal. Seus mestres têm que ser artesãos, artífices, artistas para dar conta do magistério. ... O trabalho e a relação educativa que se dá na sala de aula e no convívio entre educadores(as)/educandos(as) traz ainda as marcas da especificidade da ação educativa. A escola e outros espaços educativos ainda dependem dessa qualidade. (pp. 18-19) 
Em sua tentativa de caracterizar o trabalho docente, esse autor considera que ele envolve não apenas um saber-fazer, mas algo que vai além e que se configura como um dever-ser. Assinala também tratar-se de uma profissão que, talvez mais do que outras, se entrecruza com a vida pessoal. Por tudo isso, para o autor, o que se encontra no cerne desse ofício é algo que não se aprende em cursos, aproximando-se mais de uma experiência, na medida em que depende da vivência. Arroyo (2000) chama a atenção para o fato de que

o imaginário social configurou o ofício de mestre com fortes traços morais, éticos. No terreno do dever. Há figuras sociais de quem se espera que façam bem, com eficiência. Há outras de quem se espera que sejam boas, que tenham os comportamentos devidos, que sejam mais do que competentes. $\mathrm{O}$ magistério básico foi colocado neste imaginário. Poderemos tentar reagir enfatizando profissionalismo e eficiência, qualidade e resultados. Que como mestres ensinamos a ler, escrever, contar, que ensinamos nossa matéria competentemente. Sempre será exigido mais desse ofício. (p. 37)

O autor conclui, assim, que

ser mestre, educador, é um modo de ser e um dever-ser. Ser pedagogos de nós mesmos. Ter cuidados com nosso próprio percurso humano para assim podermos acompanhar o percurso das crianças, adolescentes e jovens. É uma conversa permanente com nós mesmos sobre a formação. (Arroyo, 2000, p. 42)

O posicionamento de Arroyo se singulariza frente ao debate sobre a questão da profissionalização ou proletarização do magistério. Sem entrar propriamente nos termos em que geralmente se trava essa discussão, por um lado, ele reflete sobre as vicissitudes que têm afetado a docência e comprometido uma atuação mais autônoma dos professores. Por outro lado, enfatiza as especificidades da atuação docente ligadas ao seu caráter não apenas relacional, mas de cuidado com elementos preciosos do humano, como lidar com a infância e a juventude justamente no processo de formação dos sujeitos nesses tempos da existência.

Em pesquisa sobre o que constitui o trabalho docente, também Maurice Tardif e Claude Lessard (2007) trazem para o primeiro plano a interatividade humana inerente ao magistério. Nesse sentido, a abordagem que propõem considera tratar-se de um trabalho fundamentalmente diferente daquele exercido por outros trabalhadores, por não se realizar sobre a matéria inerte ou sobre a matéria viva (animais, vegetais). O trabalho docente é 
entendido, por Tardif e Lessard (2007), como um trabalho interativo na medida em que é um "trabalho sobre e com o outro"'", isto é, o "objeto de trabalho" (p. 11) do professor "é justamente um outro ser humano" (p. 8).

Tardif e Lessard (2007) assinalam que, até há bem pouco tempo, "o trabalho material foi considerado o arquétipo de trabalho humano" (p. 16) e que era

o fato de estar envolvido por relações sociais de produção que definia o trabalhador e, mais que isso, o cidadão. Essas relações sociais de produção, por sua vez, eram vistas como o coração mesmo da sociedade, e o trabalho produtivo como o setor social mais essencial, aquele pelo qual se garantiam ao mesmo tempo a produção econômica da sociedade e seu desenvolvimento material. (p. 16)

Segundo Tardif e Lessard (2007), essa visão ainda prevalece, respaldando, por exemplo, as ideologias neoliberais, enquanto o trabalho dos professores

é visto como uma ocupação secundária ou periférica em relação ao trabalho material e produtivo. A docência e seus agentes ficam nisso subordinados à esfera da produção, porque sua missão primeira é preparar os filhos dos trabalhadores para o mercado de trabalho. O tempo de aprender não tem valor por si mesmo; é simplesmente uma preparação para a "verdadeira vida", ou seja, o trabalho produtivo, ao passo que, comparativamente, a escolarização é dispendiosa, improdutiva ou, quando muito, reprodutiva. (p. 17)

Entretanto, para esses autores, os modelos clássicos de trabalho, que têm como referência "o sistema produtivo de bens materiais" (Tardif \& Lessard, 2007, p. 16), não correspondem "à realidade socioeconômica das sociedades modernas avançadas" (Tardif \& Lessard, 2007, p. 17), motivo pelo qual introduzem uma outra visão, segundo eles, mais apropriada à análise das características do trabalho dos professores. Assim, a primeira tese que se propõem a defender é que "longe de ser uma ocupação secundária ou periférica em relação à hegemonia do trabalho material, o trabalho docente constitui uma das chaves para a compreensão das transformações atuais das sociedades do trabalho"7 (Tardif \& Lessard, 2007, p. 17).

Tardif e Lessard (2007) defendem ainda a tese de que "é praticamente impossível compreender o que os professores realmente fazem sem, ao mesmo tempo, interrogar-se e elucidar os modelos de gestão e de realização de seu trabalho" (p. 25) e a tese de que é "necessário ligar a questão da 
profissionalização do ensino à questão mais ampla do trabalho docente ... simplesmente por que a profissionalização coloca concretamente o problema do poder na organização do trabalho escolar e docente" (p. 27).

Dessa maneira, o magistério tem apresentado, ao longo do tempo, aspectos identitários universais compartilhados por professores de diversas partes do mundo e reconhecidos em meio ao que é próprio de cada lugar e cultura. Embora seja encarado, no senso comum, como uma carreira profissional, no dia a dia o magistério apresenta características que permitem questionar sua definição como uma profissão liberal, no sentido clássico do termo, quando se trata de examiná-la de um ponto de vista racionalmente mais elaborado. Esta divergência constitui o cerne de um importante debate que se desenvolve há algumas décadas com a participação de autores de diferentes países, como Espanha, Canadá, França, Estados Unidos, além do próprio Brasil, envolvendo os aspectos que permitiriam caracterizar o professor como um profissional ou, no outro extremo do arco ocupacional, como um trabalhador assalariado ou mesmo alguém que se dedica a essa atividade em virtude de uma vocação, entendida não apenas como um desejo ou inclinação natural, mas como uma disponibilidade para a dedicação semelhante à que geralmente se atribui ao sacerdócio.

Como explica Emilio Tenti Fanfani (2005), ao explicitar o sentido etimológico do termo "obedecer a un Ilamado":

la vocación, al igual que el sacerdocio, era una cualidad innata, una especie de
predisposición natural que los sujetos tienen o no en mayor o menor medida.
La vocación implicaba un fuerte compromiso emocional y desinteresado con la
actividad. Desde esta perspectiva, la docencia era una especie de "don" y por
eso se la asociaba con un "deber" y una "obligación", más que con un trabajo
en sentido estricto. (p. 263)

$\mathrm{Na}$ verdade, o fato de o trabalho educativo do professor da Educação Básica ser voltado para crianças e adolescentes e continuar, sob muitos aspectos, a educação usualmente recebida na família, e também por dele terem se encarregado, historicamente, congregações religiosas, o magistério foi e ainda é, muitas vezes, identificado com os cuidados maternos e com algo que se faz por amor e em atendimento a um chamado 'divino'. Essa representação do profissional docente como alguém disposto a fazer seu trabalho sem maiores preocupações com a remuneração - portanto, não como uma profissão, cujos praticantes agem de acordo com um ethos 
profissional, têm saberes e reivindicações específicas e devem ser condignamente remunerados por seu trabalho - encontra-se ainda muito difundida na sociedade, inclusive entre professores, principalmente da primeira etapa do ensino fundamental.

Ao mesmo tempo em que criticam fortemente essa ideia de vocação atrelada à "imagem do mestre divino, evangélico, salvador" (Arroyo, 2000), Miguel Arroyo e Emilio Tenti Fanfani procuram ressignificar a noção de vocação no trabalho docente. Para Arroyo (2000), "[a] idéia de vocação pode estar incrustada na idéia de profissão" (p. 33). Nas suas palavras,

Por mais que tentemos apagar esse traço vocacional, de serviço e de ideal, a figura de professor, aquele que professa uma arte, uma técnica ou ciência, um conhecimento, continuará colada à ideia de profecia, professar ou abraçar doutrinas, modos de vida, ideais, amor, dedicação. Professar como um modo de ser. Vocação, profissão, nos situam em campos semânticos tão próximos das representações sociais em que foram configurados culturalmente. São difíceis de apagar no imaginário social e pessoal sobre o ser professor, educador, docente. (Arroyo, 2000, p. 33)

O autor comenta, ademais, que o próprio fato de o professor habilitado a lecionar ser um "licenciado" vincula-se a esse ideal de serviço aos semelhantes colado à figura do professor. Em sua opinião, esta seria

uma ideia próxima à vocação, porém secularizada, politizada. Se não aceitamos ser vocacionados por Deus para o magistério, não deixamos de repetir que a educação é um dever político do Estado e um direito do cidadão, logo o magistério é um compromisso, uma delegação política. É difícil sairmos de certos traços que vêm de longe, que não perdem relevância, apenas são destacados sob um olhar secularizado. ... A identidade de trabalhadores e de profissionais não consegue apagar esses traços de uma imagem social, construída historicamente. (Arroyo, 2000, p. 33; grifo nosso)

Tenti Fanfani (2005), por meio de uma pesquisa empírica sobre a condição docente em quatro países sul-americanos - Argentina, Brasil, Peru e Uruguai -, afirma que "los datos muestran que la gran mayoría de los docentes considera a su actividad como vocacional y profesional al mismo tiempo" (p. 265). Sobre essa relação entre vocação e profissão, "lo que antes aparecía como opuesto y contradictorio ahora se presenta en forma más compleja e interrelacionada" (Tenti Fanfani, 2005, p. 265). Para o autor, mesmo sendo a origem de uma série de tensões e conflitos, a combinação de elementos vocacionais e profissionais talvez seja uma característica distintiva 
do magistério contemporâneo. Segundo ele, "nada opone la vocación a la incorporación creciente de un conocimiento técnico-científico para la solución de los problemas de aprendizaje, que son cada vez más complejos" quando esta "implica la idea de un compromiso y una actitud de responsabilidad y respeto con la persona y lo grupo de los aprendices" (Tenti Fanfani, 2005, p. 268).

Para aqueles que defendem que o magistério seja, o quanto antes e sem reservas, considerado como uma profissão no sentido pleno, essa representação pode, sem dúvida, ser considerada negativa. De fato, a compreensão de importantes aspectos que envolvem o exercício profissional dos docentes da Educação Básica, nas últimas décadas, passa bem distante da imagem da antiga 'professora primária', cuja atuação profissional supostamente era muito simples e até ingênua. A análise do que ocorre em relação ao exercício da profissão docente mostra que, na verdade, ela encontra-se hoje no centro de questões de complexidade crescente, cujos elementos constituintes nem sempre são fáceis de identificar.

Por fim, discutiremos brevemente as três dimensões da profissionalidade apontadas por Contreras (2002) e mencionadas anteriormente neste texto.

\section{A obrigação moral}

Para Contreras (2002), "o ensino supõe um compromisso de caráter moral [e ético] para quem o realiza" (p. 76). Baseado no educador estadunidense Alan Tom, o autor apresenta dois motivos que justificam tal dimensão: a) como a relação professor-aluno é uma relação assimétrica, quanto ao exercício de poder, essa desigualdade não deve ser usada contra a parte mais fraca da relação (ou seja, os alunos); b) além disso, deve-se garantir "o cuidado e a preocupação pelo bem-estar do alunado ou por boas relações com colegas e famílias" (Contreras, 2002, p. 77).

De uma maneira mais crítica, Arroyo (2000) afirma que "[o] imaginário social configurou o ofício de mestre com fortes traços morais, éticos" (p. 37). Segundo o autor, cobra-se dos professores um dever-ser. Porém, alerta sobre o fato de a "visão e interpretação tecnicista" substituirem "o imaginário amoroso e moral dos mestres por um perfil técnico" (Arroyo, 2000, p. 38). E 
responde a essa "visão tecnicista" lembrando que "[e]ducar e instruir são atos éticos e políticos" (Arroyo, 2000, p. 40). Portanto, "[a] Pedagogia não é apenas um corpo de saberes técnicos, nem sequer de saber-fazer" (Arroyo, 2000 , p. 40). Para Arroyo (2000), ao defender a "recuperação da humanidade roubada" como um traço do ofício de mestre, "ser educador é ser o mestre de obras do projeto arquitetado de sermos humanos" (p. 41).

\section{O compromisso com a comunidade}

Contreras (2002) também enfatiza o "compromisso social da prática docente" (p. 82). Para tal, espera-se dos docentes uma "dupla consciência", em que "os professores devem ser necessariamente autônomos em suas responsabilidades profissionais e, ao mesmo tempo, publicamente responsáveis" (Contreras, 2002, p. 80), o que pode se constituir, de acordo com a "retórica da profissionalização", em uma fonte de tensões e contradições na relação entre os professores e a comunidade. Isto porque, segundo o autor, essa responsabilidade pública envolve necessariamente a participação da comunidade nas decisões sobre o ensino e a escola. Ao citar os educadores estadunidenses Kenneth Zeichner e Peter McLaren, Contreras (2002), dentro da perspectiva da profissionalidade, nos lembra que "a pretensão da justiça e da igualdade social pode ter um significado intríseco à própria definição do trabalho docente" (p. 81).

\section{A competência profissional}

Para Contreras (2002), dentro da concepção de profissionalidade docente, "a competência profissional transcende o sentido puramente técnico" (p. 82). Dessa maneira, refere-se a "competências profissionais complexas que combinam habilidades, princípios e consciência do sentido e das consequências das práticas pedagógicas" (Contreras, 2002, pp. 82-83). Não se trata de "um corpus único e estabelecido de conhecimento avalizado pela pesquisa, nem compartilhado por todos os docentes", e sim de um "conhecimento que é em parte individual, produto das reelaborações sucessivas dos docentes a partir de sua experiência, em parte compartilhado, por obra dos intercâmbios entre professores e processos comuns de socialização, e em parte diversificado, produto de diferentes tradições e 
posições pedagógicas" (Contreras, 2002, p. 83). Não se trata de "um conhecimento proposicional, facilmente explicitável e formulável", e sim de "um saber que, embora se nutra de diversas fontes e experiências, adquire uma dimensão fundamentalmente prática, isto é, que tem na ação o principal referente" (Contreras, 2002, p. 83). Por fim, "[também] faz parte das competências profissionais o modo em que se criam e se sustentam vínculos com as pessoas, em que a cumplicidade, o afeto e a sensibilidade se integram e se desenvolvem nas formas de viver a profissão" (Contreras, 2002, p. 85).

Arroyo (2000) acredita que essa competência profissional é construída coletivamente por meio do estabelecimento de "comunidades de aprendizes mútuos": "Os aprendizes se ajudam uns aos outros a aprender, trocando saberes, vivências, significados, culturas" (p. 166). Dentro dessa concepção, "[a] escola é uma comunidade especializada na aprendizagem de todos os seus membros. É uma comunidade de aprendizes que se apóiam uns nos outros, de aprendizes mútuos, com o professor como mediador, orquestrando os procedimentos. Sem medo de perder nosso saber-fazer de ofício" (Arroyo, 2000, p. 167).

\section{Considerações finais}

Em seu livro, Ofício de Mestre - Imagens e auto-imagens, Miguel Arroyo (2000) levanta as seguintes questões sobre o magistério: "Como a categoria pensa em si mesma? No espelho dos outros ou no próprio espelho?" (p. 13). Ao deixar se encantar pela "retórica da profissionalização" - e a fortíssima influência que a vertente funcionalista exerce sobre esse conceito -, o magistério parece insistir em olhar para si mesmo "no espelho dos outros".

Como defendemos neste artigo, o maior desafio é justamente não se deixar seduzir pelo "discurso do profissionalismo", para que o magistério possa mirar-se "no próprio espelho". Para tal, o conceito de profissionalidade e a busca da especificidade da ação docente apresentam-se como ideias que podem abrir novos horizontes não somente para se repensar o sentido do magistério em si, mas também, e fundamentalmente, para a busca da construção de uma sociedade verdadeiramente democrática, mais justa, mais igualitária, mais humana e mais fraterna. É imprescindível ressaltar, por fim, 
que tal processo deve se dar concomitantemente à denúncia e à resistência aos processos brutais de precarização, intensificação e aumento de controle sobre o trabalho docente, de diminuição da autonomia profissional, de aviltamento salarial dos professores e de desqualificação profissional.

\section{Notas}

1 Este texto subsidiou a participação do autor no Simpósio "Profissionalização docente: Teias, tramas e nexos", no dia 24 de agosto de 2016, dentro da programação do XVIII Encontro Nacional de Didática e Prática de Ensino (ENDIPE), em Cuiabá, Mato Grosso.

2 É oportuno registrar que Sociologia das Profissões não é o mesmo que Sociologia do Trabalho. A área da Sociologia que se tornou conhecida como Sociologia das Profissões tornou-se assim conhecida devido ao grande volume de contribuições especificamente sobre as ocupações às quais se aplicava o modelo profissional.

3 Havia a opinião de que sindicalizar-se era comportamento "impróprio" para os praticantes das profissões clássicas, o que, para grupos profissionais que aspiravam atingir o status de profissionais, tinha efeito desmobilizador.

4 A primeira é que os profissionais devem ter uma competência específica, obtida em curso de formação de nível universitário. Além disso, "seu saber tem um componente 'sagrado', no sentido de que não pode ser avaliado pelos profanos. Só um profissional pode julgar a outro, e só a profissão pode controlar o acesso de novos membros, já que só ela pode garantir e avaliar sua formação" (Enguita, 1991, p. 43). A segunda característica é que o profissional exerce sua profissão, supostamente, pelo desejo de servir a seus semelhantes, isto é, por vocação, de modo que "seu trabalho não pode ser pago, porque não tem preço, seu exercício é 'liberal' e sua retribuição toma a forma de 'honorários'" (Enguita, 1991, p. 44). A terceira é que o exercício da profissão é privativo, isto é, apenas tem licença para exercê-la quem tem "competência técnica" e "vocação de serviço". Daí a origem dos termos 'licenciado', 'faculdade', etc. A quarta refere-se ao fato de que os profissionais têm independência "no exercício de sua profissão: frente às organizações e frente aos clientes" (Enguita, 1991, p. 44), pois exercem sua profissão de maneira liberal, sem o controle de patrões, e também porque os clientes os procuram com "necessidades, problemas ou urgências que só o profissional sabe como resolver" (Enguita, 1991, p. 44), diferentemente de clientes de outros serviços, que "sempre têm razão". E, por fim, a quinta diz respeito ao fato de que existe uma autorregulação da atuação profissional "com base na identidade e na solidariedade grupal" (Enguita, 1991, p. 44) e em um código de ética próprio e órgãos que resolvem seus conflitos internos.

5 No livro Trabalho e capital monopolista, de 1974.

6 As quatro "ideias nucleares" são as seguintes: 1) a análise do trabalho educacional está referenciada pelas condições de trabalho que, de acordo com Marx, foram gestadas, no capitalismo, no âmbito da produção. Essas condições incluem as 
"medidas impostas pela 'lógica racionalizadora do capital"', as quais estão relacionadas à desqualificação, à alienação e à perda de controle em relação ao próprio trabalho; 2) a transposição desta lógica para o trabalho educacional se expressa com a chegada, à escola, de materiais e pacotes tecnológicos diversos para serem usados pelos professores, assim como pela chegada de especialistas, entre outras medidas que excluem os professores das funções de concepção e planejamento; 3) tudo isto tem gerado conflitos na escola, sendo que os professores apresentam diversas formas de resistência; 4) tudo isto estaria provocando a proletarização da categoria dos docentes, sendo possível, portanto, comparar sua situação à de outros trabalhadores.

7 Para Tardif e Lessard (2007), esta tese se apóia nas seguintes constatações: 1) tem havido um declínio cada vez maior do efetivo dos trabalhadores produtores de bens materiais nas últimas cinco décadas nos Estados Unidos, Canadá e Europa; 2) os profissionais ligados aos serviços vinculados à sociedade da informação ou do conhecimento têm ocupado cargos cada vez mais importantes em comparação àqueles ocupados pelos produtores de bens materiais; 3 ) as profissões que estão surgindo se relacionam "historicamente às profissões e aos profissionais que são representantes típicos dos novos grupos de especialistas na gestão dos problemas econômicos e sociais com auxílio de conhecimentos fornecidos pelas ciências naturais e sociais" (p. 19); e 4) "entre as transformações em curso, parece essencial observar o crescente status de que gozam, na organização socioeconômica, nas sociedades modernas avançadas, os ofícios e profissões que têm seres humanos como 'objeto de trabalho"' (p. 19).

\section{Referências}

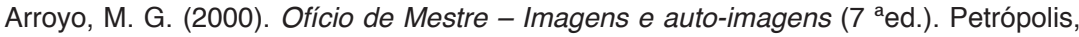
RJ: Editora Vozes.

Barbosa, M. L. O. (1993). A Sociologia das Profissões: Em torno da legitimidade de um objeto. Revista Brasileira de Informação Bibliográfica em Ciências Sociais (BIB), 36, 3-30.

Bonelli, M. G. (1993). As Ciências Sociais no sistema profissional brasileiro. Revista Brasileira de Informação Bibliográfica em Ciências Sociais (BIB), 36, 31-61.

Cabrera, B., \& Jaén, M. J. (1991). Quem são e que fazem os docentes: Sobre o "conhecimento" sociológico do professorado. Teoria \& Educação, 4, 190-214.

Chapoulie, J. M. (1973). Sur l'analyse sociologique des groupes professionnels. Revue Française de Sociologie, 14(1), 86-114.

Contreras, J. (2002). A autonomia de professores. São Paulo: Cortez.

Costa, M. C. V. (1995). Trabalho docente e profissionalismo. Porto Alegre: Sulina.

Dubar, C. (1997). A socialização - Construção das identidades sociais e profissionais. Porto: Porto Editora.

Enguita, M. F. (1991). A ambigüidade da docência: Entre o profissionalismo e a proletarização. Teoria \& Educação, 4, 91-108. 
Gimeno Sacristán, J. (1995). Consciência e acção sobre a prática como libertação profissional dos professores. In A. Nóvoa (Org.), Profissão professor (pp. 6392). Porto: Porto Editora.

Hughes, E. C. (1964). Men and their work (2nd ed.). Glencoe, Illinois: The Free Press.

Jaén, M. J. (1991). Os docentes e a racionalização do trabalho em educação: Elementos para uma crítica da teoria da proletarização dos docentes. Teoria \& Educação, 4, 74-89.

Larson, M. S. (1977). The rise of professionalism: A sociological analysis. Berkeley/Los Angeles/London: University of California Press.

Larson, M. S. (2014). Looking back and a little forward: Reflections on professionalism and teaching as a profession. Radical Teacher - A Socialist, Feminist, and Antiracist Journal on the Theory and Practice of Teaching, 99, 7-17.

Le Bianic, T. (2005). Les "ingénieurs des âmes". Savoirs académiques, professionnalisation et pratiques des psychologues du travail de l'entre deux guerres à nos jours (Tese de doutorado). Université de la Méditerranée - AixMarseille II, Laboratoire d'Economie et de Sociologie du Travail, France.

Popkewitz, T. S. (1997). Profissionalização e formação de professores: Algumas notas sobre a sua história, ideologia e potencial. In A. Nóvoa (Coord.), Os professores e a sua formação (pp. 35-50). Lisboa: Publicações Dom Quixote/Instituto de Inovação Educacional.

Tardif, M., \& Lessard, C. (2007). O trabalho docente: Elementos para uma teoria da docência como profissão de interações humanas ( $3^{\mathrm{a}}$ ed.). Petrópolis, RJ: Vozes.

Tenti Fanfani, E. (2005). La condición docente: Análisis comparado de la Argentina, Brasil, Perú y Uruguai. Buenos Aires: Siglo XXI Editores.

Zeichner, K. M. (2008). Formação de professores para a justiça social em tempos de incerteza e desigualdades crescentes. In J. E. Diniz-Pereira \& K. M. Zeichner (Orgs.), Justiça social: Desafio para a formação de professores (pp. 11-34). Belo Horizonte: Autêntica. 


\title{
LOOKING AT TEACHING THROUGH "ITS OWN MIRROR:" THE CONCEPT OF PROFESSIONALITY AND THE POSSIBILITIES OF RETHINKING THE MEANING OF TEACHING PROFESSION
}

\begin{abstract}
In his book Ofício de Mestre - Imagens e auto-imagens, Professor Emeritus at Federal University of Minas Gerais, in Brazil, Miguel Arroyo, raises the following questions about teaching: "How does the teaching profession think about itself? Through the mirror of others or through its own mirror?". By letting oneself be led by the "illusion of professionalization" - and the very strong influence that the functionalist view exerts on this concept -, the teaching profession seems to insist on looking at itself "through the mirror of others." In this article, by discussing the concepts of professionalization, professionalism and professionality, as well as a review of the sociology of professions, we discuss the following questions on this topic: what does it mean to consider that teaching is, in fact, a profession? What are the implications of referring to the concepts of professionalization, professionalism and professionality in the description of the performance and of the expectations placed for the teacher as a professional? What are the possibilities of rethinking the meaning of the teaching profession through the concept of professionalism? In the end, we defend the use of the concept of professionalism to discuss the specificity of the teaching profession - that is, "to make it look at its own mirror" - and that the concept opens new possibilities for rethinking the meaning of the teaching profession.
\end{abstract}

Keywords

Teaching profession; Professionality; Sociology of professions; Brazil 


\section{MIRAR EL MAGISTERIO "EN SU PROPRIO ESPEJO": EL CONCEPTO DE PROFESIONALIDAD Y LAS POSIBILIDADES DE REPENSAR EL SIGNIFICADO DE LA PROFESIÓN DOCENTE}

\section{Resumen}

En su libro Ofício de Mestre - Imagens e auto-imagens, el Profesor Emérito de la Universidad Federal de Minas Gerais, en Brasil, Miguel Arroyo, plantea las siguientes preguntas acerca de la profesión docente: "¿En qué medida la categoría piensa en si misma? ¿En el espejo de los otros o en su propio espejo?". Dejando seducirse por la "ilusión de la profesionalización" - y la influencia muy fuerte que el aspecto funcionalista tiene en este concepto -, el magisterio parece insistir en mirar a sí mismo "en el espejo de los otros". En este artículo, a través de la discusión de los conceptos de profesionalización, profesionalismo y profesionalidad y una revisión de la sociología de las profesiones, se discuten las siguientes preguntas sobre este tema: ¿Qué significa considerar que el magisterio constituye, de hecho, una profesión? ¿Cuáles son las implicaciones de referirse a los conceptos de profesionalización, profesionalismo y profesionalidad en la descripción de los resultados y de las expectativas puestas al maestro como un profesional? ¿Cuáles son las posibilidades para repensar el significado del magisterio a partir del concepto de profesionalidad? Al final, abogamos por el uso del concepto de profesionalidad para discutir la naturaleza específica de la profesión docente - es decir, hacerla mirar "en su propio espejo" - y como esto abre nuevas posibilidades para repensar el significado del magisterio.

Palabras-clave

Profesión docente; Profesionalidad; Sociología de las profesiones; Brasil

Recebido em janeiro/2017

Aceite para publicação em março/2017

i Instituto de Geo-Ciências, Universidade Federal de Minas Gerais, Brasil.

ii Programa de Pós-Graduação em Educação, Universidade Federal de Minas Gerais, Brasil.

Toda a correspondência relativa a este artigo deve ser enviada para: Júlio Emílio Diniz-Pereira, Universidade Federal de Minas Gerais, Avenida Antônio Carlos, 6.627, Belo Horizonte, MG, 31.270901, Brasil. E-mail: juliodiniz@ufmg.br 